\title{
Breaking the Back of COVID-19: Is Bangladesh Doing Enough Testing?
}

\author{
Md Hasinur Rahaman Khan ${ }^{1, *}$ and Tamanna Howlader ${ }^{2}$ \\ ${ }^{1,2}$ Institute of Statistical Research and Training, University of Dhaka, Bangladesh \\ ${ }^{1}$ Corresponding author: hasinur@isrt.ac.bd
}

Received: May 10, 2020; revised: June 27, 2020; accepted: July 12, 2020.

\begin{abstract}
Following detection of the first 100 confirmed cases of COVID-19 in early April, Bangladesh stepped up its efforts to strengthen testing capacity in order to curb the spread of the disease across the country. This paper sheds light on the position of Bangladesh in relation to its South Asian neighbors India and Pakistan with respect to testing capacity and ability to detect cases with increased testing. It also analyzes recent data on case counts and testing numbers in Bangladesh, to provide an idea regarding the number of extra tests needed to detect a substantial number of cases within a short period of time. Findings indicate that compared to India and Pakistan, Bangladesh was able to detect more cases by increasing testing levels and expand its testing capacity by performing more per capita tests. In spite of these achievements, the rate of reported cases per 100 tests was consistently higher for Bangladesh compared to India, which suggests that in addition to increased testing, other factors, such as, effective enforcement of social distancing and efficient contact tracing are just as important in curbing the spread of the disease. The analysis reveals that current testing levels in Bangladesh are not adequate. Based on the findings, we recommend a $5-15 \%$ growth of the current test rate in the next day so that by detecting and isolating more cases, Bangladesh could, in effect, contain the spread of new infections. The challenge, however, is to mobilize resources necessary to expand geographical coverage and improve testing quality while enforcing social distancing and performing efficient contact tracing.
\end{abstract}

Keywords: Coronavirus, COVID19 disease, COVID19 test, Bangladesh, India, Pakistan

\section{Introduction}

The severe acute respiratory syndrome coronavirus (SARS-CoV-2) pandemic fully established itself in Bangladesh in early April when the number of infected persons crossed the 
100-th mark. Prior to this time, the country detected its first three coronavirus cases on 8 March 2020 confirmed by the Institute of Epidemiology, Disease Control and Research (Institute of Epidemiology and Disease Control and Research, 2020). The country detected three more cases of COVID-19 on March 16 taking the total number of infected persons to 8 (Khan and Hossain, 2020b). On March 18 the country witnessed its first COVID-19 death. Since then, the number of new infections continued to rise as Bangladesh ramped up the number of tests performed. By 27-th of June, 715,098 tests had been performed as the disease spread to all the 64 districts and the country counted 133,978 cases and a death toll of 1695 persons (Institute of Epidemiology and Disease Control and Research, 2020), (Khan, 2020).

Increasing the level of testing has been regarded as one of the most important tools in the fight against the disease. Testing leads to quick identification of cases and immediate isolation as well as treatment to prevent further spread. Once cases are identified, contact tracing may be performed to identify exposed individuals so that they too can be quickly isolated and treated if symptoms arise (Hellewell et. al., 2020). Thus, more and more testing helps to curb the spread and to flatten the curve and take the pressure off the health care system (Ravelo, 2020). In the case of South Korea, where there was high testing coverage, experts believe that testing played a major role in controlling the COVID-19 pandemic. The key to their success was a large, well-organized testing program combined with extensive efforts to isolate infected people and trace and quarantine their contacts. By 16-th of March, South Korea had tested more than 270,000 people, many of whom were tested at a network of dozens of drive-through testing stations. This strategy, which has since been followed elsewhere, eased access to testing and prevented infected people from exposing others in waiting rooms (Cohen and Kupferschmidt, 2020). Another country, Australia has conducted a high number of tests (As of June 4, about 58 total tests per thousand people), which is more than the US, Canada or South Korea have done per thousand. The comparison with South Korea, which has been widely praised for its handling of the pandemic, is especially notable and reflects well on Australia. An additional advantage of widespread testing of "presumed COVID" patients who are not hospitalized is that it gives a far clearer picture of this new viral disease, which we currently have so little data about (Rosenthal, 2020). Thus, testing is important in the bigger public health picture on mitigation efforts, helping investigators characterize the prevalence, spread and contagiousness of the disease (Sanchez, 2020).

By June 26, the China administered the highest number of tests, i.e. over 90.4 million, which is over $39 \%$ of the global test total (231 million) while USA is the second highest i.e. 31.3 million, which is about 13.6. Russia ranked third having conducted 18.4 million tests, UK ranked fourth with over 8.9 million tests, and India ranked fifth having performed approximately 7.8 million tests up till June 26 . Testing levels have differed widely across countries. Heterogeneity has been observed in testing capacity both within and between countries due to differences in factors such as financial resources, laboratory capacity and availability of qualified technicians. Healthcare systems in low and middle income countries such as Bangladesh have faced the greatest challenges in expanding their testing capacity due to limited resources.

Although there have been a number of research works on COVID-19 in Bangladesh, very few have focused on testing. For instance, Khan and Hossain (2020a) analyzed global data and concluded that cumulative number of tests is not an important variable to predict the number of infections. Other studies on COVID-19 in Bangladesh include (Khan et al., 
2020; Islam et al., 2020b; Paul et al., 2020; Mamun and Griffiths, 2020; Shahidul et al., 2020; Anwar et al., 2020; Islam and Ayesha, 2020; Islam et al., 2020a). As of May 5, Bangladesh performed 567 tests per million people, while its South Asian neighbors India and Pakistan performed 864 and 1,007 tests per million, respectively over the same period. A question that arises is, 'Has Bangladesh conducted an adequate number of tests to restrict the spread of COVID-19?' In a country where majority of the people are poor and uneducated, enforcing social distancing measures can be challenging. Thus, adequate testing is required to identify and isolate cases to curb the spread of the disease, especially among the poor masses. This article attempts to answer the question of adequate testing by analyzing COVID-19 related data on Bangladesh until June 21, 2020 and evaluating the country's position in relation to India and Pakistan.

\section{Methodology}

The data are collected from worldometers.info website (Max Roser and Ortiz-Ospina, 2020). We considered data reported as of June 21, 2020 for three countries Bangladesh, India and Pakistan. Furthermore the data pertaining to Bangladesh has been cross checked with the Bangladesh government's source (Institute of Epidemiology and Disease Control and Research, 2020). Basic statistical tools for exploratory data analysis have been used.

Basic exploratory data analysis techniques, such as trend line, scatter plot, rates, descriptive statistics have been used to either display or analyse the data. Pearson's correlation coefficient has been used to measure the strength of linear association between daily number of tests and infections. However, a linear regression model has been used to predict the number of daily infections.

\section{Analysis}

Figure 1 (top panel) shows a plot of the number of daily infections per million due to COVID19 against number of days since the first 100 cases was identified in Bangladesh, India and Pakistan. The time series for Bangladesh is shorter than that for India and Pakistan because the first 100 cases were recorded earlier in the latter two countries. The three curves corresponding to the three countries demonstrate exponential increases in the number of daily infections. During the first 7 days, Bangladesh had nearly the same number of infections per million per day as Pakistan. Both countries exceeded the daily number of infections per million recorded in India. However after the 7th day, the number of daily infections recorded in Bangladesh began to rise far above that of India and Pakistan. Although India had a lower number of daily case counts per million initially during the outbreak, the numbers began to climb after the 50th day while it was seen for Pakistan and Bangladesh after the 43rd and 34th days, respectively. The rapid increase in the slope of the curve for Bangladesh relative to India and Pakistan during the later stages of the outbreak suggests that COVID-19 may be spreading more quickly in Bangladesh. However, one must keep in mind that this graph does not take into account differences in the numbers of tests performed in the three countries.

The plot in Figure 1 (bottom panel) shows the number of daily deaths per million against the number of days since 100 confirmed cases for Bangladesh, India and Pakistan. It can be seen that the number of recorded deaths per million was higher for Bangladesh compared to the other two countries from day 1 to day 21 while it was parallel to Pakistan and above 


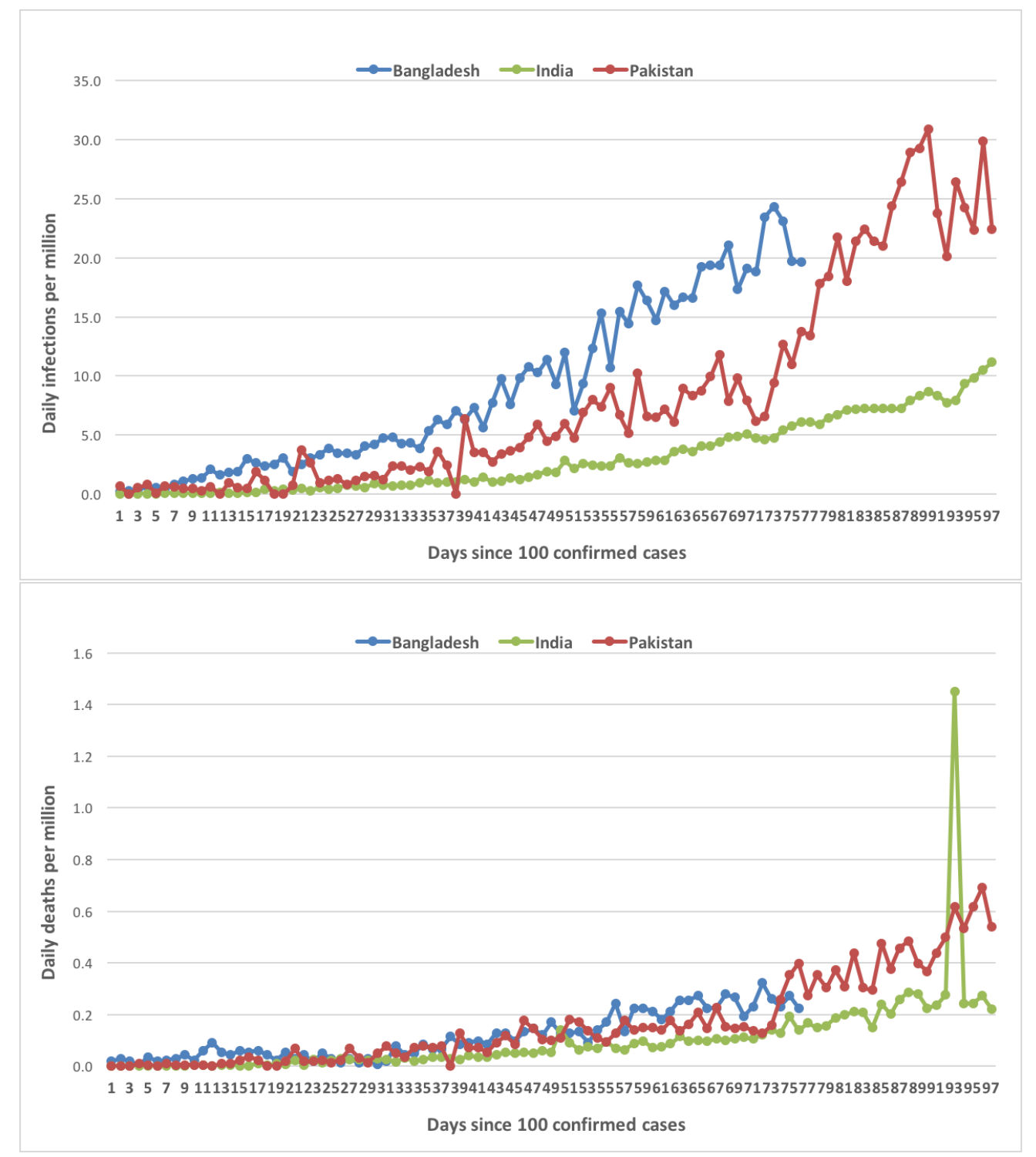

Figure 1: Daily infections and deaths per million of Bangladesh, India and Pakistan since their 100 confirmed cases. 


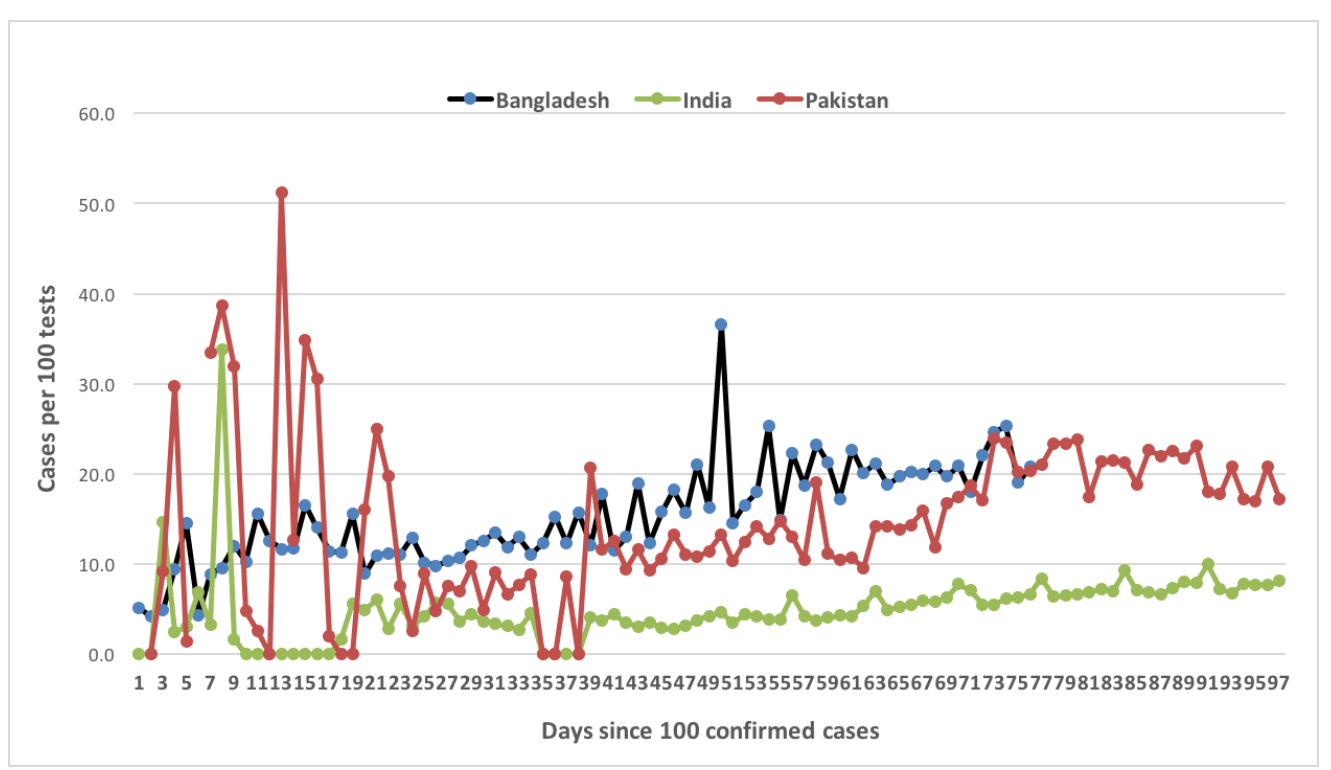

Figure 2: Confirmed cases per 100 tests of Bangladesh, India and Pakistan since their 100 confirmed cases

India from day 22 to day 55 . As the days progressed from day 55, the death toll per million in Bangladesh rose and was well above that of India and Pakistan till the 74th day. Since day 75, the curves for Pakistan is well above India and Bangladesh that indicating Pakistan is having higher rate of deaths, which is far above the India and Bangladesh. The rate of increase in daily deaths per million for India was consistently lower than that of Bangladesh and Pakistan and continued to be lower during this time.

Figure 4 indicates that there is a positive correlation between number of tests conducted and number of cases identified. Thus, the number of cases per 100 tests is a useful measure to compare disease frequency between countries because it controls for the number of tests that have been performed. Figure 2 shows the number of cases per 100 tests in the days following identification of the first 100 cases for Bangladesh, India and Pakistan. Compared to Bangladesh and Pakistan, the number of confirmed cases was lower for India, i.e. less than 10 cases per 100 tests, for most of the duration of the time series. Initially, Bangladesh also recorded less than 10 cases per 100 tests, but after the 10 th day, the number of cases began to rise and the ratio hovered between 10 to 25 cases per 100 tests. The time series for Pakistan was erratic during the first 24 days with several peaks exceeding 20 cases per 100 tests and one peak reaching as high as 50 cases per 100 tests. Over the next 14 days, the ratio remained within the $0-10$ band and then jumped to slightly over 20 cases per 100 tests on the 39th day. It then declined and remained steady within the 10-20 band till 73rd day and since 74th day it was between 15-25. Overall this graph, which gives an idea of the disease frequency after controlling for the number of tests performed, suggests that India may have been better able to control the spread of the disease compared to the other two countries.

Testing is regarded as one of the most effective ways to deal with the rapidly spreading COVID-19 disease because it gives authorities the opportunity to isolate infected cases and 


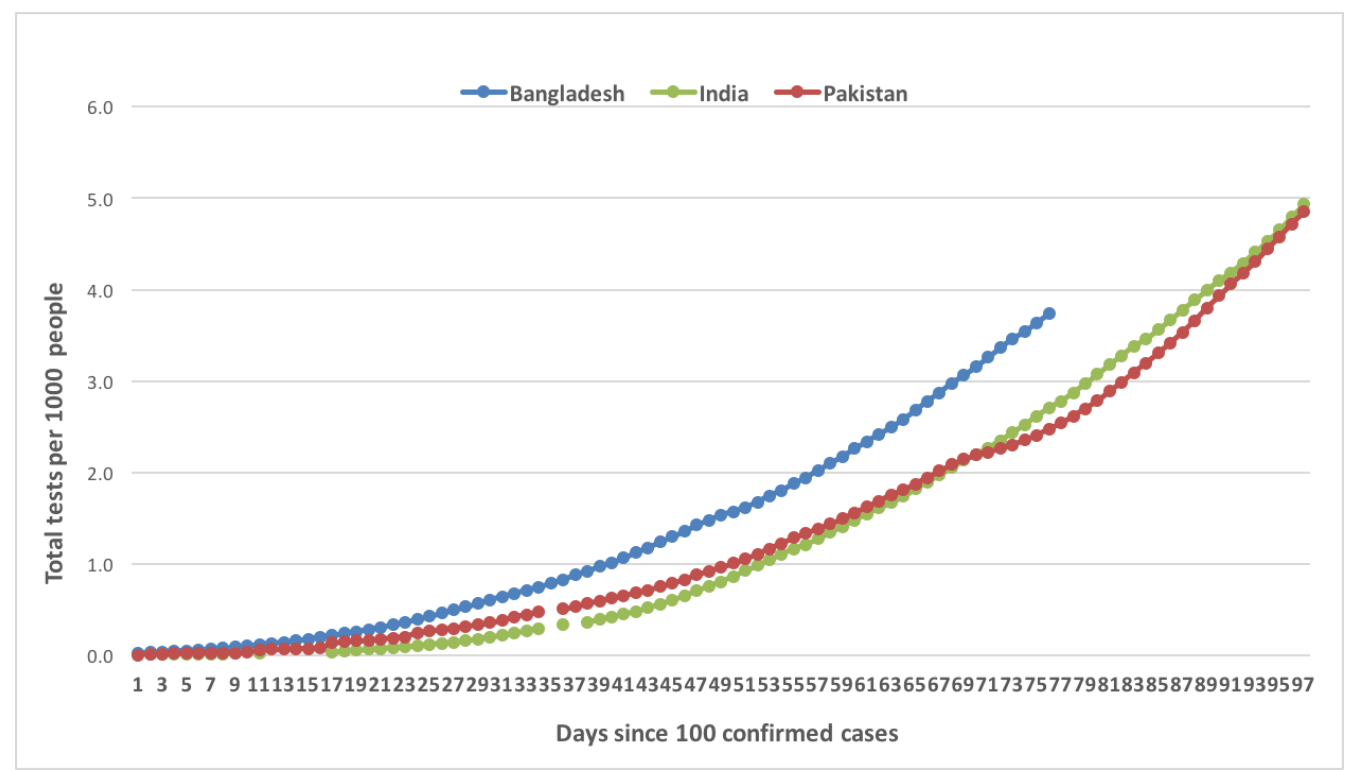

Figure 3: Number of tests per 1000 people of Bangladesh, India and Pakistan since their 100 confirmed cases

stem the spread of the disease. Figure 3 shows the number of tests performed per 1000 people against number of days since 100 confirmed cases for Bangladesh, India and Pakistan. There appears to be an exponential increase in the number of tests performed over time for all three countries. However, Bangladesh appears to have had the highest level of testing followed by Pakistan after controlling for population size. This seems to indicate that Bangladesh has done a good job at expanding its testing capacity compared to India and Pakistan.

In terms of daily number of tests, Bangladesh down-performs India and Pakistan as found from the daily data (Max Roser and Ortiz-Ospina, 2020). But when the number of tests are adjusted by the country's population, then Bangladesh outperforms India and Pakistan as shown in Figure (3). Is the current level of daily tests enough to slow down the spread? To search for an answer, we analyzed the data in a way that provides some idea regarding the increment in the daily growth of tests needed to slow down the spread of the virus in Bangladesh. Table (1) shows the number of daily tests, number of cases, rate of confirmed cases in 100 tests, growth rate of the daily test in last 10 days, average of last 10 day's daily rate of confirmed cases in 100 tests. The last six columns show the total number of tests required and the resulting total number of infections, if a specific increment (5\%, 10\% and $15 \%$ ) in the daily test rate that needs to be added to the next day's test for slowing down the spread. It appears from the analysis of last 11 days data from June 16 to June 26 that the case finding rate per 100 tests is averaged at 22 . That is, on an average 22 cases are reported as positive in every 100 tests although a significant number of tests had been increased i.e. from 17214 (June 16) to 18498 (June 26)- which is 7.5\% increment. In spite of such increments, the case finding rate was found to be fixed at around 22 . This is true for 
Table 1: Dynamics of COVID-19 tests in Bangladesh

\begin{tabular}{|c|c|c|c|c|c|c|c|c|c|c|c|}
\hline \multirow[t]{2}{*}{ Day } & \multirow[t]{2}{*}{$\begin{array}{l}\text { Daily } \\
\text { tests }\end{array}$} & \multirow{2}{*}{$\begin{array}{c}\text { Daily } \\
\text { confirmed } \\
\text { infections }\end{array}$} & \multirow{2}{*}{$\begin{array}{c}\text { Cases } \\
\text { per } 100 \\
\text { tests }\end{array}$} & \multirow{2}{*}{ 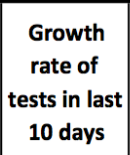 } & \multirow{2}{*}{$\begin{array}{c}\text { Average of } \\
\text { cases per } \\
100 \text { tests in } \\
\text { last } 10 \text { days }\end{array}$} & \multicolumn{2}{|c|}{$\begin{array}{l}\text { If } 5 \% \text { test is } \\
\text { increased to the } \\
\text { next day }\end{array}$} & \multicolumn{2}{|c|}{$\begin{array}{l}\text { If } 10 \% \text { test is } \\
\text { increased to the } \\
\text { next day }\end{array}$} & \multicolumn{2}{|c|}{$\begin{array}{l}\text { If } 15 \% \text { test is } \\
\text { increased to the } \\
\text { next day }\end{array}$} \\
\hline & & & & & & Tests & Infections & Tests & Infections & Tests & Infections \\
\hline 16-Jun & 17214 & 3862 & 22.4 & 37.9 & 20.7 & & & & & & \\
\hline 17-Jun & 17527 & 4008 & 22.9 & 33.4 & 20.9 & 18075 & 3785 & 18935 & 3965 & 19796 & 4145 \\
\hline 18-Jun & 16259 & 3803 & 23.4 & 25.6 & 21.2 & 18978 & 4017 & 20829 & 4408 & 22766 & 4818 \\
\hline 19-Jun & 15045 & 3243 & 21.6 & 2.6 & 21.2 & 19927 & 4216 & 22912 & 4848 & 26180 & 5539 \\
\hline 20-Jun & 14031 & 3240 & 23.1 & -12.1 & 21.5 & 20924 & 4492 & 25203 & 5411 & 30107 & 6464 \\
\hline 21-Jun & 15585 & 3531 & 22.7 & -1.2 & 21.7 & 21970 & 4770 & 27723 & 6020 & 34624 & 7518 \\
\hline 22-Jun & 15555 & 3480 & 22.4 & -2.7 & 21.8 & 23068 & 5024 & 30496 & 6642 & 39817 & 8672 \\
\hline 23-Jun & 16292 & 3412 & 20.9 & -2.1 & 22.2 & 24222 & 5367 & 33545 & 7433 & 45790 & 10146 \\
\hline 24-Jun & 16433 & 3462 & 21.1 & 13.3 & 22.1 & 25433 & 5620 & 36900 & 8154 & 52658 & 11637 \\
\hline 25-Jun & 17999 & 3946 & 21.9 & 19.7 & 22.2 & 26705 & 5936 & 40590 & 9023 & 60557 & 13462 \\
\hline 26-Jun & 18498 & 3868 & 20.9 & 7.5 & 22.1 & 28040 & 6191 & 44649 & 9857 & 69640 & 15375 \\
\hline Total & 180438 & 39855 & 243 & 122 & 238 & 227342 & 49418 & 301782 & 65760 & 401934 & 87775 \\
\hline Average & 16403 & 3623 & 22 & 11 & 22 & 22734 & 4942 & 30178 & 6576 & 40193 & 8777 \\
\hline 27-Jun & 16403 & 3623 & 22.0 & 11.0 & 22.0 & 19423 & 4273 & 20348 & 4477 & 21273 & 4680 \\
\hline 28-Jun & 16403 & 3623 & 22.0 & 11.0 & 22.0 & 20394 & 4487 & 22383 & 4924 & 24464 & 5382 \\
\hline 29-Jun & 16403 & 3623 & 22.0 & 11.0 & 22.0 & 21414 & 4711 & 24621 & 5417 & 28133 & 6189 \\
\hline 30-Jun & 16403 & 3623 & 22.0 & 11.0 & 22.0 & 22484 & 4947 & 27083 & 5958 & 32353 & 7118 \\
\hline 1-Jul & 16403 & 3623 & 22.0 & 11.0 & 22.0 & 23609 & 5194 & 29791 & 6554 & 37206 & 8185 \\
\hline 2-Jul & 16403 & 3623 & 22.0 & 11.0 & 22.0 & 24789 & 5454 & 32770 & 7209 & 42787 & 9413 \\
\hline 3-Jul & 16403 & 3623 & 22.0 & 11.0 & 22.0 & 26029 & 5726 & 36047 & 7930 & 49205 & 10825 \\
\hline 4-Jul & 16403 & 3623 & 22.0 & 11.0 & 22.0 & 27330 & 6013 & 39652 & 8723 & 56586 & 12449 \\
\hline 5-Jul & 16403 & 3623 & 22.0 & 11.0 & 22.0 & 28696 & 6313 & 43617 & 9596 & 65074 & 14316 \\
\hline 6-Jul & 16403 & 3623 & 22.0 & 11.0 & 22.0 & 30131 & 6629 & 47979 & 10555 & 74835 & 16464 \\
\hline 7-Jul & 16403 & 3623 & 22.0 & 11.0 & 22.0 & 31638 & 6960 & 52777 & 11611 & 86060 & 18933 \\
\hline 8-Jul & 16403 & 3623 & 22.0 & 11.0 & 22.0 & 33220 & 7308 & 58055 & 12772 & 98969 & 21773 \\
\hline 9-Jul & 16403 & 3623 & 22.0 & 11.0 & 22.0 & 34881 & 7674 & 63860 & 14049 & 113814 & 25039 \\
\hline 10-Jul & 16403 & 3623 & 22.0 & 11.0 & 22.0 & 36625 & 8057 & 70246 & 15454 & 130886 & 28795 \\
\hline Total & 229642 & 50722 & 308 & 154 & 308 & 380662 & 83746 & 569229 & 125230 & 861644 & 189562 \\
\hline Average & 16403 & 3623 & 22 & 11 & 22 & 27190 & 5982 & 40659 & 8945 & 61546 & 13540 \\
\hline
\end{tabular}

other dates as well. Hence, this analysis suggests that Bangladesh had to increase number of tests to a number of percentage to the next day to lower the case finding rate.

Table (1) shows the predicted number of infections against the predicted number of tests for last 11 days (from June 16-26) and also for the next 14 days (from June 27-July 10). It is found that if tests could have been increased to the next day at $5 \%, 10 \%$ and $15 \%$ rate for June $16-26$ period then total $227,342,301,782$ and 401,934 tests could detect total 49,418 , 65,760 and 87,775 infections respectively against the actual total number of 180,438 tests and 39,855 infections. Hence, we could find 2.2 times more cases than the actual cases (daily average 8,777 ) if we could increase $15 \%$ tests to the next day during the period of June 16-26. For the next 14 days (from June 27-July 10) we assumed that the daily rate of confirmed cases in 100 tests would be similar to 22 that is found as the average over June 16-26 period. It reveals from Table (1) that if tests are increased to the next day at $5 \%$, 


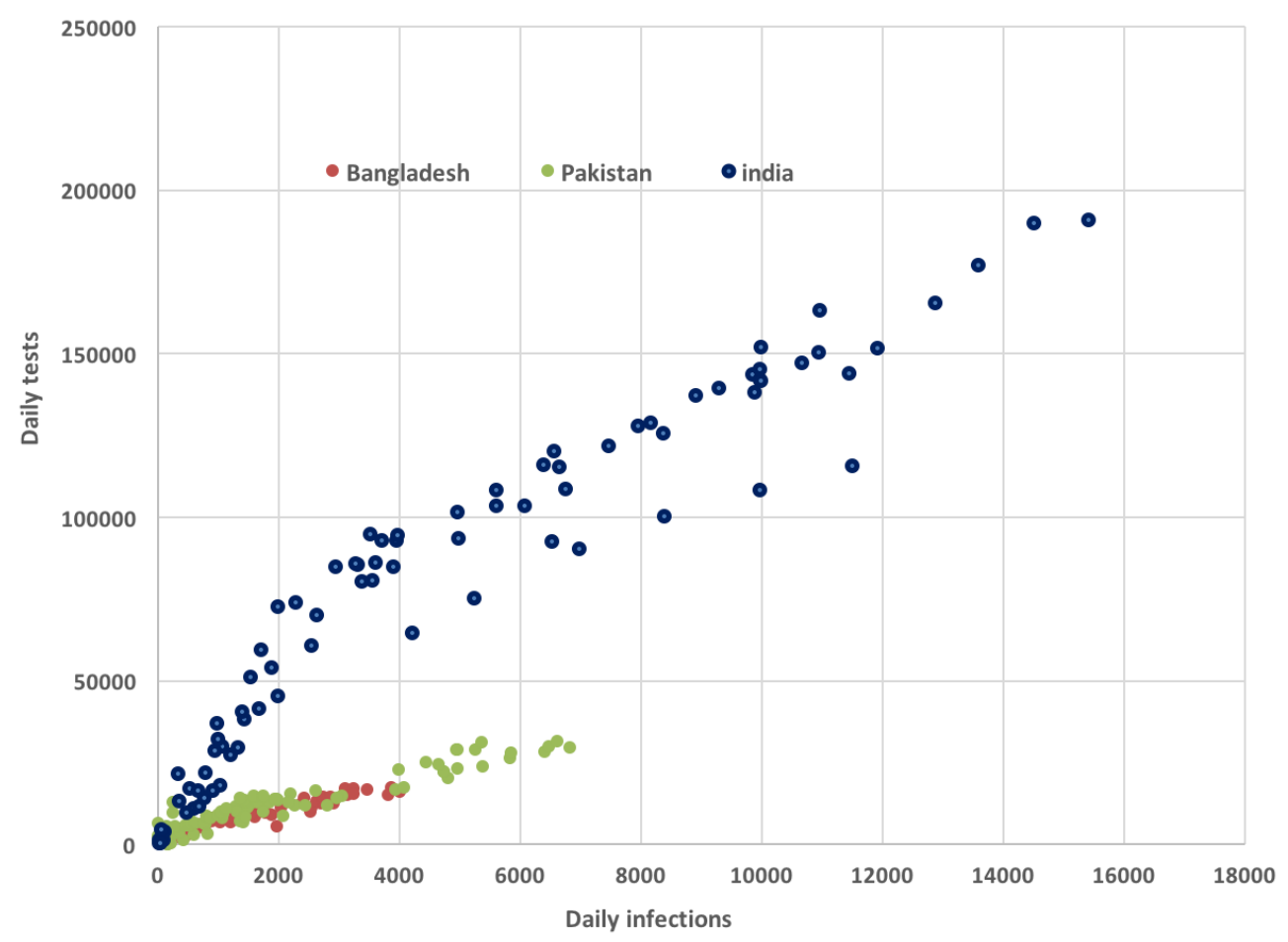

Figure 4: Scatter plot between the number of daily tests and confirmed cases for Bangladesh, India and Pakistan

$10 \%$ and $15 \%$ rate for June 27-July 10 period then total 380,662, 569,229 and 861,664 tests will detect total $83,746,125,230$ and 189,562 infections respectively against the total number of 229,642 tests and 50,722 infections found using the average number of tests and infections in June 16-26 period. Hence, we may find more than 3.7 times more cases than the projected cases (daily average 13,540 against the projected 3,623) if we could increase $15 \%$ tests to the next day during the period of June 27- July 10.

It should be noted that there is very strong positive correlation $(r=0.98)$ between the daily tests and the confirmed cases for Bangladesh while there is strong positive association $(r=0.95)$ for both countries India and Pakistan (see Figure (4)). This also suggests that Bangladesh has consistently been able to detect higher number of cases with increased testing. Similar relationship between testing levels and case counts is observed for India and Pakistan although the countries have observed slightly less consistency in detecting cases than Bangladesh in this respect. Thus, although Bangladesh appears to be outperforming India and Pakistan in terms of greater case detection through increased testing (Figure (2)), it needs to go for rapid testing expansion. A 5-15\% daily growth for the next day or even doubling of the current week test rate in next week could help detect more cases and aid in controlling the virus spread within a short period of time. 


\section{Conclusions}

Increased testing is seen as one of the most important strategies for combating the COVID19 pandemic. The positive association between testing and the number of reported cases suggests that more cases will be identified and subsequently isolated with an increase in the number of tests performed. This is in turn will have the effect of slowing down the spread of the virus throughout the population. The objective of this paper has been to assess whether the current level of testing in Bangladesh is sufficient to curb the spread of the virus and to draw comparisons with two important South Asian countries, namely, India and Pakistan. Preliminary analysis revealed an exponential trend in daily population adjusted case counts for all three countries during the first 97 days after the 100th case was found indicating that all three countries were in the tertiary stages of the epidemic. Bangladesh had a consistently higher population adjusted daily infections than India and Pakistan.

Bangladesh had a higher population adjusted daily death count than India and Pakistan till the 24-th day since the first 100 cases were identified after which the death toll in India and Pakistan surpassed that of Bangladesh till 55-th day. But from 55-th to 75-th day again Bangladesh had a higher daily population adjusted death count. Plots of number of cases per 100 tests against time revealed that Bangladesh had higher numbers of reported cases compared to India and Pakistan on average. However, Pakistan had higher values for this ratio on several occasions in the beginning compared to Bangladesh including one occasion where the ratio was three folds higher. The consistently lower levels of reported cases per 100 tests over time indicate that India may have been more successful in controlling the spread of the virus compared to Bangladesh and Pakistan. Graphs for total tests per 1000 people against time showed exponential increases in the level of testing for all three countries. However, the curve for Bangladesh was higher than that of India and Pakistan indicating that Bangladesh has been more successful in expanding its testing capacity with respect to its population size. In spite of this achievement, Bangladesh has observed higher numbers of reported cases per 100 tests than India, which seems to indicate that in addition to increased testing, other factors, such as, effective enforcement of social distancing and efficient contact tracing may also be important in curbing the spread of the disease.

This study also found that Bangladesh needed to increase every day (to the next day) a minimum $5 \%$ and maximum $15 \%$ of tests to lower the case finding rate during June 26 to July 10 . If tests are increased to the next day at 5\%, 10\% and $15 \%$ rate for June 27-July 10 period then total $380,662,569,229$ and 861,664 tests will detect total $83,746,125,230$ and 189,562 infections respectively against the total number of 229,642 tests and 50,722 infections that are found using the average number of tests and infections that took place in June 16-26 period. Hence, we may find more than 3.7 times more cases than the projected cases (daily average 13,540 against the projected 3,623) if we could increase $15 \%$ tests to the next day during the period of June 27- July 10. We also found that Bangladesh has consistently been able to detect higher number of cases with increased testing. This has been observed for India and Pakistan as well although with slightly less consistency. In spite of outperforming India and Pakistan with respect to per capita testing levels, Bangladesh needs to go for rapid testing expansion, such as 5-15\% daily growth for the next day or even doubling of the current week figure in next week to detect more cases. We firmly believe in that the strategies of next day increment by $5-15 \%$ are pragmatic and viable with the current economic conditions of Bangladesh. This, in effect, would help to curb the spread of the disease through greater contact tracing and isolation. 


\section{Declarations}

Funding: There was no funding available for this study.

Conflict of interest: We declare that we have no conflict of interest.

Ethical approval: Not applicable.

\section{References}

Anwar S, Nasrullah M, Hosen M (2020). "COVID-19 and Bangladesh: Challenges and How to Address Them." Front. Public Health, 8(154). doi:http://dx.doi.org/10.3389/fpubh.2020.00154.

Cohen J, Kupferschmidt K (2020). "Countries test tactics in 'war' against COVID-19.” Science, 367(6484), 1287-1288.

Hellewell et al (2020). "Feasibility of controlling COVID-19 outbreaks by isolation of cases and contacts." The Lancet Global Health, 8(4), 488-496.

Institute of Epidemiology and Disease Control and Research (2020). "Bangladesh Coronavirus Update." URL http://www.corona.gov.bd.

Islam $\mathrm{M}$, Talukder $\mathrm{A}$, Siddiqui $\mathrm{M}$, Islam $\mathrm{T}$ (2020a). "Tackling the Pandemic COVID-19: The Bangladesh Perspective." Preprints. doi:http://dx.doi.org/10.20944/preprints202004.0384.v1.

Islam MD, Ayesha S (2020). "COVID-19 and Bangladesh: A Study of the Public Perception on the Measures Taken by the Government." EdArXiv. doi:http://dx.doi.org/10.13140/RG.2.2.30042.49608.

Islam MM, Islam MM, Hossain MJ, Ahmed F (2020b). "Modeling risk of infectious diseases: a case of Coronavirus outbreak in four countries,." medRxiv. doi:http://dx.doi.org/10.1101/2020.04.01.20049973.

Khan MHR (2020). "Covid-19 (Coronavirus) in Bangladesh." Daily Report, (Report No. 29-06052020). URL https://sites.google.com/site/teachingsitehasinur/corona.

Khan MHR, Hossain A (2020a). "Countries are Clustered but Number of Tests is not Vital to Predict Global COVID-19 Confirmed Cases: A Machine Learning Approach." medRxiv. doi:Doi: 10.1101/2020.04.24.20078238.

Khan MHR, Hossain A (2020b). "COVID-19 Outbreak Situations in Bangladesh: An Empirical Analysis." medRxiv. doi:Doi: 10.1101/2020.04.16.20068312.

Khan MHR, Howlader T, Islam MM (2020). "Battling the COVID-19 Pandemic: Is Bangladesh Prepared?” medRxiv. doi:http://dx.doi.org/10.1101/2020.04.29.20084236.

Mamun MA, Griffiths MD (2020). "First COVID-19 suicide case in Bangladesh due to fear of COVID-19 and xenophobia: Possible suicide prevention strategies." Asian Journal of Psychiatry, 51(102073).

BRR Www.jBiomedAnalytics.org 
Max Roser HR, Ortiz-Ospina E (2020). "Coronavirus Disease (COVID-19) ? Statistics and Research." Our World in Data. URL https://ourworldindata.org/coronavirus.

Paul A, Chatterjee S, Bairag N (2020). "Prediction on Covid-19 epidemic for different countries: Focusing on South Asia under various precautionary measures." medRxiv. doi:http://dx.doi.org/10.1101/2020.04.08.20055095.

Ravelo LJ (2020). "A look at COVID-19 testing and why country-wide is impossible right now." pp. Accessed April 30, 2020. URL https://www.devex.com/news/.

Rosenthal E (2020). "The Real Tragedy of Not Having Enough Covid-19 Tests." Opinion in The New York Times.

Sanchez E (2020). "COVID-19 science: Why testing is so important." pp. Accessed April 28, 2020. URL https://www.heart.org/en/news/2020/04/02/ covid-19-science-why-testing-is-so-important, \{April2\}.

Shahidul Islam M, Irana Ira J, Ariful KK, Kamrujjaman M (2020). "COVID-19 Epidemic Compartments Model and Bangladesh." Preprints. doi:http://dx.doi.org/10.20944/preprints202004.0193.v1. 